Revista de Estudios Histórico-Jurídicos

[Sección historia del derecho patrio chileno]

XXXVIII (Valparaíso, Chile, 2016)

[pp. 305 - 330]

\title{
EL MODELO NORMATIVO DEL SINDICATO EN LAS LEYES SOCIALES DE 1924*
}

[The Union's Normative model in the Social Security Act of 1924]

\author{
Irene ROJAS Miño** \\ Universidad de Talca, Chile
}

\begin{abstract}
RESUMEN
Dado el principio de libertad sindical, este trabajo cuestiona la regulación establecida por las Leyes Sociales de 1924 en lo referido a la definición de una estructura sindical y de dos tipos específicos de sindicatos, el industrial de empresa y el profesional, además, se interroga las consecuencias de dicha definición normativa en el ámbito del sistema de relaciones laborales, en especial respecto de los niveles de sindicalización y de acción colectiva. A efectos de una respuesta a tales interrogantes, se da cuenta del rol de la legislación en el ámbito de las relaciones colectivas de trabajo y de los antecedentes de la dictación de las leyes sociales; asimismo, se analiza la tipología sindical establecida en las leyes sociales de 1924, los fundamentos
\end{abstract}

\begin{abstract}
Given the principle of union freedom, this article questions the regulation stipulated by the Social Security Act of 1924 regarding the definition of a union structure and of two specific kinds of unions: the industrial, pertaining to the enterprise, and the professional unions. Likewise, the consequences of said normative definition within the scope of labour relationships system, especially regarding the unionisation levels and collective actions, are questioned. In order to provide an answer to the aforementioned issues, the role of the regulations within the scope of the collective labour relationships and of the background of the social security laws enactment is analysed; also, the union
\end{abstract}

RECIBIDO el 16 de octubre de 2015 y ACEPTADO el 11 de julio de 2016

\footnotetext{
* Este artículo forma parte del Proyecto de Investigación de la Universidad de Talca, titulado "Las particularidades del sistema de fuentes del Derecho del Trabajo en Chile".

** Profesora Asociada Universidad de Talca. Dirección Postal: Sede Santiago de Universidad de Talca, Calle Santa Elena, 2222, Comuna de San Joaquín, Santiago, Chile. Correo Electrónico: irojas@utalca.cl.
} 
de las propuestas de dicha estructura sindical y el impacto de su aplicación en el sistema de relaciones laborales chileno. laboral.
Palabras clave

Sindicato - Leyes Sociales - Legislación classification established in the social security act of 1924, the grounds of the proposals of said union structure and the consequences of their application in the Chilean labour relationships system are analysed.

\section{KEYWORDS}

Union - Social Security Act - Labour legislation.

\section{INTRODUCCIÓN}

Como es sabido, en Chile han existido diversos modelos normativos de relaciones laborales ${ }^{1}$. El primero de ellos fue el del Código del Trabajo de 1931, el que tuvo su origen en las Leyes Sociales de 1924 y cuya vigencia se prolongó hasta el año 1973, en el que con ocasión del golpe militar se suspende la aplicación de parte de su normativa, siendo derogado en su totalidad hacia fines de la década de los años setenta con la entrada en vigencia de los textos legales del siguiente modelo normativo, el del Plan Laboral.

Pues bien, las Leyes Sociales de 1924 establecieron una regulación de las relaciones individuales y colectivas de trabajo, las que definieron un determinado sistema jurídico de relaciones laborales. Dicho sistema jurídico planteó rasgos específicos, y ello tanto en el orden individual como colectivo. Entre otros rasgos se plantea que la ley definió al sindicato en la base del sistema productivo a través del establecimiento del sindicato industrial en la empresa y el sindicato profesional o de oficio, desatendiendo, de esta manera, las otras vías en que estaban organizados los trabajadores, ya sea a nivel territorial ${ }^{2}$ y de sector económico ${ }^{3}$.

En una perspectiva universal e independientemente del sistema jurídico, es cuestionable la definición legal de la estructura sindical, en cuanto como señalan los Convenios de la Organización Internacional del Trabajo - en adelante, OIT- sobre la libertad sindical: "los trabajadores y los empleadores, sin ninguna distinción y sin autorización previa, tienen el derecho de constituir las organizaciones que estimen convenientes, así como el de afiliarse a estas organizaciones, con la sola condición de observar los estatutos de las mismas"; reiteradamente que "el libre ejercicio del derecho de constituir sindicatos y de afiliarse

${ }^{1}$ Como señala Ojeda, Antonio, La confrontación de modelos sociales en el cambio de siglo, en Revista Trabajo y Seguridad Social [España], 379 (octubre 2014), p. 17, el modelo normativo alude al conjunto de rasgos típicos del núcleo sustantivo del Derecho del Trabajo "que presta unidad e impulsa en una dirección concreta el entero sistema de relaciones laborales".

${ }^{2}$ Como era la Federación Obrera de Chile, FOCH, como sindicato de carácter nacional. Al respecto, BARría Jorge, Los movimientos sociales de Chile. Desde 1910 hasta 1926 (Santiago, Editorial Universitaria, 1960).

${ }^{3}$ Como son los trabajadores del sector portuario, quienes se organizaron de acuerdo al ideario anarquista como sección chilena de Trabajadores Industriales del Mundo, IWW -Industrial Workers of World-. BARRÍA, Jorge, cit. (n.2), pp. 170-172.

${ }^{4}$ Artículo 2 de Convenio 87 de 1948 de Organización Internacional del Trabajo. 
a los mismos implicaba la libre determinación de la estructura y la composición de estos sindicatos"s.

Pues bien, frente a la opción política legislativa efectuada en las Leyes Sociales de 1924 surgen diversas interrogantes: en primer lugar, por qué se definió una estructura sindical y por qué en ella se establecieron estos tipos de sindicatos, en circunstancias que la realidad de entonces, incluida la de los sistemas comparados, planteaban diversas alternativas. En segundo lugar, qué consecuencias tuvo esta definición normativa en el ámbito del sistema de relaciones laborales, en especial respecto de los niveles de sindicalización y de acción colectiva.

Este trabajo pretende responder dichas preguntas. A estos efectos, además de dar cuenta del rol de la legislación en el ámbito de las relaciones colectivas de trabajo y de los antecedentes de la dictación de las leyes sociales, se analiza la tipología sindical establecida en las leyes sociales de 1924, los fundamentos de las propuestas de dicha estructura sindical y el impacto de su aplicación en el sistema de relaciones laborales chileno.

Debe señalarse que este particular tema, del cuestionamiento de la estructura sindical establecido en las leyes sociales de 1924 y luego en el Código del Trabajo de 1931, ha sido escasamente objeto de estudio y evaluación tanto por parte de los historiadores como por la doctrina laboralista chilena.

En efecto, por parte de los historiadores sociales se ha realizado el estudio del movimiento de trabajadores en sus distintas etapas, cubriendo el período "la cuestión social" que antecede a la legislación laboral, pero dicho análisis no incorpora un análisis de dicha normativa, sino que ésta es asumida como parte de un "nuevo pacto" junto con el Estado de compromiso ${ }^{6}$. En todo caso, en este ámbito es relevante el estudio que se efectúa de la posición del movimiento de los trabajadores respecto de la legislación laboral ${ }^{7}$, particularmente en el período previo a la dictación de la misma. Aunque tradicionalmente se había sostenido la posición rupturista de las organizaciones de trabajadores con el sistema y, por consiguiente, se asumía el rechazo a la intervención legal en las relaciones de trabajo; en los últimos años se plantea una revisión de tal tesis, pues se sostiene que el movimiento de trabajadores tuvo diversas posiciones frente a la legislación laboral ${ }^{8}$.

No obstante, sí se plantean excepciones respecto de la carencia de estudios sobre

5 Organización Internacional del Trabajo, OIT, Comité de Libertad Sindical del Consejo de Administración, Recopilación de decisiones y principios del Comité de Libertad Sindical del Consejo de Administración de la OIT (5 a dición, Ginebra, Oficina Internacional del Trabajo, 2006), p. 74.

${ }^{6}$ Salazar, Gabriel y Pinto, Julio, Historia contemporánea de Chile, III: La economía: mercados, empresarios y trabajadores (séptima reimpresión, Santiago, Ed. Lom, 2012), p. 175.

7 Sobre la posición de los trabajadores frente a la legislación laboral véase Sección II.

${ }^{8}$ Entre ellos, YÁNEZ, Juan, Antecedentes y evolución histórica de la legislación social de Chile entre 1906 y 1924, en REHJ. 21 (1999); GREZ, Sergio (2002), El escarpado camino hacia la legislación social: debates, contradicciones y encrucijadas en el movimiento obrero y popular [Chile: 1901-1924]" [en http://www.memoriachilena.cl/archivos2/pdfs/MC0043163.pdf, visto el 15 de enero de 2016]); Mellado, Vicente, ¡Por el derecho de asociación y de huelga! La Federación Obrera de Chile (FOCH) y el camino a la legislación laboral (1921-1924), en Cuadernos de Historia 42 (Santiago, 2015), pp. 85-125. 
el contenido de esta legislación, tal como es la obra de James Morris ${ }^{9}$, la que precisamente plantea como uno de sus objetivos, un "estudio de la génesis y los primeros años de desarrollo del sistema legal de relaciones industriales chileno" ${ }^{10}$, y si bien es de cincuenta años atrás, su análisis mantienen plena vigencia Las demás obras son relativamente recientes, tal cual son las de Yañez Andrade ${ }^{11}$, Grez Toso ${ }^{12}$ y Mellado Carrasco $^{13}$, todas las cuales, junto con la de Morris, fueron de gran relevancia en esta publicación. En todo caso, estas publicaciones no se refieren a la interrogante planteada en este estudio -por qué se estableció en las Leyes Sociales de 1924 la estructura sindical señalada-, aunque James Morris sí plantea algunos antecedentes para dicha respuesta.

Por parte de la doctrina del Derecho el Trabajo se requiere distinguir entre la del período en que estuvo vigente dicho modelo normativo de las Leyes Sociales de 1924 -y, por ende, del Código del Trabajo de 1931-y la que es posterior al mismo.

La primera doctrina laboralista, constituida por los profesores de la disciplina del Derecho del Trabajo del período 1930 a 1973, en general no efectuaron un análisis crítico de la normativa laboral, sino que mayoritariamente realizaron un análisis de índole técnico jurídico ${ }^{14}$, aunque sí calificaron de intervencionista la normativa laboral en materia sindical, como es la obra de Gaete Berríos ${ }^{15}$ y Walker Linares ${ }^{16}$; distinguiendo, este último, entre la intervención legislativa de la estructura sindical y la administrativa, dado que ésta "somete a los sindicatos a una sumisión excesiva respecto a Estado [...]"17. En todo caso, sí hubo análisis de política legislativa realizado a través de estudios monográficos, como fue respectos de específicas materias, tal como fueron, entre otros, los referidos a la huelga de Humeres Magnan ${ }^{18}$, y a la evolución del Derecho Social en América, de Poblete Troncoso ${ }^{19}$.

9 Morris, James, Las elites, los intelectuales y el consenso. Estudio de la Cuestión Social y del sistema de Relaciones Industriales en Chile (INSORA, Departamento de Relaciones Industriales de la Universidad de Chile, Santiago, Ed. del Pacífico, 1967.

${ }^{10}$ Ibíd., p. 11.

11 De Yáñez, Juan, cit (n. 8). Así también del mismo autor, Yáñez, Juan, El Proyecto Laboral de la FOCH (1921). Los trabajadores frente a la Legislación Social, en GREZ, Sergio (ed.) Espacio de Convergencia, Primer y Segundo Encuentro de Estudios Humanísticos para investigadores jóvenes (Santiago, Ed, Museo Vicuña Mackenna, 2001).

12 Grez, Toso, cit. (n. 8).

13 Mellado, Vicente, cit. (n. 8). Así también, del mismo autor, Mellado, Vicente, El Código del Trabajo y los proyectos de legislación laboral de la Federación Obrera de Chile. Ponencia presentada en las XXI Jornadas de Historia de Chile 4, 5 y 6 de noviembre de 2015 (en http:// www.cimtra.cl/ponencia-presentada-en-las-xxi-jornadas-de-historia-de-chile-inseguridad-estadoy-transformaciones-sociales-4-5-6-de-noviembre-de-2015/, visitado el 15 de enero de 2015).

14 Por todos, de Humeres M., Héctor, Apuntes de Derecho del Trabajo y de Seguridad Social (Décima edición, Santiago, Ed. Jurídica de Chile, 1973), pp. 281 a 299.

15 GaEte, Alfredo, Tratado de Derecho del Trabajo Chileno (Santiago, Ed. Jurídica de Chile, 1960), pp. 215 y 216.

${ }^{16}$ En este sentido, Walker L., Francisco, Esquema del Derecho del Trabajo y de la Seguridad Social (Santiago, Ed. Jurídica de Chile, 1965), p.134.

17 Ibíd.

${ }^{18}$ De Humeres M. Héctor, La huelga (Santiago, Ed. Jurídica de Chile, 1957).

19 Poblete, Moisés, Evolución del Derecho Social en América (Santiago, Editorial Nascimento, 1942), 480 pp. 
Por su parte la doctrina laboralista posterior a la vigencia del Código del trabajo de 1931 y, por consiguiente, contemporánea al modelo normativo del Plan Laboral y las respectivas reformas laborales, no ha efectuado un análisis en profundidad de la normativa sobre relaciones colectivas de trabajo en las Leyes Sociales de 1924 y tampoco sobre la especial materia de la estructura sindical, aunque diversos autores también han calificado de intervencionista dicha normativa ${ }^{20}$, como también lo es la actual normativa de las relaciones colectivas de trabajo ${ }^{21}$, valoración a la que se suman otros autores ${ }^{22}$. Pero algunos autores sí han efectuado análisis específicos en determinadas áreas, tal como son: el modelo de negociación de colectiva ${ }^{23}$, el trabajo de la mujer y la división de roles de género ${ }^{24}$, la regulación de la libertad sindical, en general ${ }^{25}$, y del fuero laboral ${ }^{26}$.

\section{El Derecho del trabajo y el rol de la legislación}

LABORAL

Si bien, las dos grandes áreas de regulación del Derecho del Trabajo son las relaciones individuales y las relaciones colectivas de trabajo, las que respectivamente constituyen su centro imputación normativa ${ }^{27}$, en sus orígenes el Derecho del Trabajo regula principalmente las relaciones individuales de trabajo, a fin de establecer derechos mínimos en favor del trabajador, y ello lo hace a través de un instrumento privilegiado al efecto y que es la ley. Sin embargo, conjunta o posteriormente, será también la ley la que en muchos casos establezca una regulación respecto de los institutos de las relaciones colectivas, sea la organización de trabajadores, la negociación colectiva o la huelga. Pero en muchos casos esta intervención legal ha sido cuestionada.

Precisamente ha sido respecto de las relaciones colectivas de trabajo que la intervención legislativa plantea objetivos más diferenciados. Desde permitir la existencia de los diversos institutos del Derecho Sindical, derogando a tal efecto las prohibiciones que recaían sobre los mismos, tal como se plantea en una primera etapa respecto de los sindicatos, la negociación colectiva o la huelga -como es la supresión de la

${ }^{20}$ En este sentido, RojAs, Irene, La legislación laboral en Chile en el ámbito de las relaciones colectivas del trabajo: control de la autonomía colectiva, en Ius et Praxis, 6 (2000), 2, pp. 378380); Gamonal C., Sergio, Derecho Colectivo del Trabajo (Santiago, Ed. LexisNexis, 2002), pp. 29-30, 40-43.

21 Ibíd.

${ }^{22}$ En este sentido, entre otros, TAPIA, Francisco (1993), Intervención y autonomía en las relaciones de trabajo en Chile, en ERMIDA U., Oscar, Intervención y autonomía en las relaciones colectivas de trabajo (Montevideo, Ed. Fundación de Cultura Económica, 1993), pp. 105-112.

${ }^{23}$ Rojas, Irene, La experiencia histórica de la negociación colectiva en Chile, en DIRECCIÓN DEL Trabajo (ed.), La negociación colectiva en Chile. La debilidad de un derecho imprescindible (Santiago, Ed. Dirección del Trabajo, 2009), pp. 73-108.

24 CaAmaño, Eduardo, Mujer, trabajo y derecho (Santiago, Ed. Abeledo Perrot, 2011), pp. $1-14$.

25 Toledo C., César (2013). Tutela de la libertad sindical (Santiago, Ed. Thomson Reuters, 2013), pp. 14-18.

26 Ibíd., pp. 57-70.

${ }^{27}$ SALA, Tomás, Derecho sindical (Valencia, Ed. Tirant lo Blanch, 2013), p. 19. 
Ley francesa Le Chapelier de $1791^{28}$-, o regular estas instituciones a fin de alcanzar diversos fines de carácter sociopolíticos, tal como se plantea en muchos de nuestros países latinoamericanos, hasta el establecimiento de una 'legislación promocional', tal como ha ocurrido en diversos sistemas de relaciones laborales ${ }^{29}$.

Para comprender esta diversidad en una perspectiva global, debe recordarse que el Derecho del Trabajo como disciplina jurídica nace en un determinado contexto histórico: el del trabajo realizado por personas libres en un sistema capitalista y en un marco jurídico de supuesta igualdad de las partes y de abstencionismo del Estado, quien finalmente reacciona y entra a regular dichas relaciones estableciendo derechos mínimos en favor de los trabajadores.

Sin embargo, tal como ha sido estudiado en diversos sistemas políticos, esta intervención legal no respondió a un fin tutelar o, al menos, no se funda sólo en dicho objetivo, sino que atiende "a la integración del conflicto entre el trabajo asalariado y el capital, en términos compatibles con la existencia del sistema económico capitalista" ${ }^{30}$. En este proceso de integración del conflicto laboral, el Estado asume diversos roles en el ámbito de las relaciones colectivas, desde la versión totalitaria del Estado como organizador social, pasando por la versión controladora, hasta llegar a la de carácter democrática ${ }^{31}$.

La versión totalitaria se caracteriza "por la construcción coactiva de una unidad social, económica y política, bajo la dirección del poder político" 32 , propio de algunos sistemas que existieron en el siglo veinte, en los que admite al sindicato pero este debe estar inserto y depender del aparato estatal. La versión controladora del Estado responde a diversas causas ${ }^{33}$, las que paradójicamente se reúnen en el conjunto de países latinoamericanos, con la excepción de Uruguay, pero será el factor político el

${ }^{28}$ La que precisamente prohibía la organización sindical y la negociación colectiva. Al respecto, Exposición de Motivos de la Ley Chapelier establecía: “Debe, sin duda, permitirse a los ciudadanos de un mismo oficio o profesión celebrar asambleas, pero no se les debe permitir que el objetivo de esas asambleas sea la defensa de sus pretendidos intereses comunes; no existen corporaciones en el Estado, y no hay más interés que el particular de cada individuo y el general, no puede permitirse a nadie que inspire a los ciudadanos la creencia de un interés intermedio que separe a los hombres de la cosa pública por un espíritu de corporación."

29 Como han sido, a vía de ejemplo, la Ley Wagner de Estados Unidos, de 1935, el Estatuto de los Trabajadores de Italia, de 1970, y el Estatuto de los Trabajadores de España, de 1980.

30 Palomeque Manuel, Derecho del Trabajo e ideología (7a edición, Madrid, Ed. Tecnos, 2011), p. 34.

31 Si bien, la doctrina distingue tradicionalmente entre versión autoritaria y versión democrática -en este sentido, BAYlos, Antonio, Derecho del Trabajo. Modelo por armar (Madrid, Ed. Trotta, 1991), pp. 29-38-, debe incorporarse la versión de control sindical, propia de países latinoamericanos, en este sentido, ERMIDA, Oscar, Intervención y autonomía en las relaciones colectivas de trabajo latinoamericanas: situación actual y perspectivas, en ÉL MISMO (coord.), Intervención y autonomía en las relaciones colectivas de trabajo (Montevideo, Fondo de Cultura Universitaria, Montevideo, 1993), pp. 379-390.

32 Baylos, Antonio, cit. (n. 31), p. 30.

${ }^{33}$ Como señala Ermida, Oscar, cit. (n. 31), p. 380), en los orígenes del Derecho del Trabajo se presentan en mayor o menor medida "algunos comunes denominadores": la falta de una negociación colectiva sectorial o generalizada en la etapa de los orígenes de la economía capitalista, una tendencia legalista, en el plano jurídico, el objetivo del control del sindicato en la perspectiva política y la debilidad sindical en el plano social. 
que pretenda el control del sindicato y de su acción y que se manifiesta en la regulación de los diversos aspectos de organización y de acción del sindicato ${ }^{34}$. Por último, está la versión democrática, en que reconociendo el conflicto, se establecen a la vez los derechos de libertad sindical y, por consiguiente, el de la autonomía colectiva, configurándose el Derecho del Trabajo con sus dos grandes fuentes normativas: la ley y los acuerdos colectivos.

A partir de mitad del siglo veinte -con el reconocimiento internacional del principio de libertad sindical y de los derechos que los integran ${ }^{35}$, a través de los Convenios 87, de 1948, y 98, de 1949, de la Organización Internacional del Trabajo, como también en base a la Declaración Universal de los Derechos Humanos de Naciones Unidas, de $1948^{36}$-, es la versión democrática la que se acoge en el Derecho Internacional del Trabajo y en la mayoría de los ordenamientos jurídicos.

Precisamente, en base a los Convenios de Libertad Sindical, la OIT ha rechazado el control estatal respecto de los sindicatos, tanto en la improcedencia de una autorización previa para su constitución ${ }^{37}$, la intervención del Estado en la organización de sus actividades y en la formulación de su programa de acción ${ }^{38}$ y la disolución por decisión de la autoridad administrativa ${ }^{39}$.

\section{LAS RELACIONES LABORALES EN EL PERÍODO ANTERIOR A}

\section{LAS LEYES SOCIALES}

En Chile, hasta inicios del siglo veinte,la regulación de la relación laboral individual quedaba sujeta a la autonomía contractual. A partir de entonces, la primera década del siglo veinte, el Estado dicta algunos textos legales a fin de establecer específicas protecciones en favor de los trabajadores tanto en las relaciones individuales de trabajo como en la seguridad social ${ }^{40}$.

${ }^{34}$ Como sostiene Ermida, Oscar, ibíd., pp. 381-382), “[...] la reglamentación heterónoma de los sindicatos en Latinoamérica es asimétrica, no ya porque tenga caracteres de promoción, soporte o apoyo a la acción sindical, sino por lo inverso: por ser más reglamentarista, exigente, limitadora y restrictiva con los sindicatos de trabajadores, que con las organizaciones de empleadores, y asimismo, por ser más proclive a la reglamentación estructural del sindicato que a la protección de la acción sindical”.

${ }^{35}$ Recuérdese que el principio de libertad sindical se concibe como los derechos y garantías de los trabajadores y de sus organizaciones para constituir organizaciones sindicales, afiliarse a ellas y desarrollar actividad sindical para defensa de sus intereses, entre los que se cuentan, necesariamente, los derechos de negociación colectiva y de huelga. Sin embargo, como señaló Plá, Américo, Los sindicatos en Uruguay, en Pasco, Mario y ACKerman, Mario (coords.), Los sindicatos en Iberoamérica (Lima, Ed. Aele, 1988), p. 376, se plantean inconvenientes al encerrar este principio en una definición: “[...] la plasticidad del concepto, revela una mayor elasticidad y amplitud que la realidad, siempre cambiante y novedosa, del mundo del trabajo va creando siempre".

${ }^{36}$ Declaración que en su Artículo 23 apartado $4^{\circ}$ establece “toda persona tiene el derecho de fundar sindicatos y el de afiliarse a éstos para la defensa de sus intereses".

37 Organización InTERnacional del Trabajo, cit. (n. 5), pp. 61-62.

${ }^{38}$ Ibíd., pp. 109-114.

39 Ibíd., pp. 146-147.

40 De ese período son los siguientes textos normativos: Ley de Habitaciones Obreras 
En el ámbito de las relaciones colectivas, se presentan organizaciones de trabajadores -en donde predominaron las sociedades de sociedades de socorro mutuo ${ }^{41}$, las sociedades de resistencia ${ }^{42}$, las mancomunales ${ }^{43} y$, en una última etapa, los sindicatos-, como también negociaciones colectivas, conflictos colectivos y huelgas, principalmente en los sectores más dinámicos de la economíay que, a la vez, presentaban algún grado de concentración de trabajadores asalariados, como son las actividades mineras del norte del país -es decir del salitre-, también las faenas relacionadas con las actividades portuarias de Valparaíso, las actividades industriales de Santiago y la minería del carbón ${ }^{44}$. Fue en estos sectores en donde se plantearon los primeros conflictos laborales, los que si bien se originan desde mitad del siglo 19, el aumento de los mismos comienza con posterioridad a la Guerra del Pacífico ${ }^{45}$, según anota Ramírez Necoechea ${ }^{46}$.

Si bien en Chile en la etapa previa de la dictación de las Leyes Sociales no se dictaron normas especiales para prohibir estas manifestaciones de las relaciones colectivas, como sí ocurrió en otros sistemas ${ }^{47}$, el Estado, en base a la misma ideología liberal que sostiene su posición de no intervención en las relaciones laborales, desconoce legitimidad a la actuación de la organización de los trabajadores -sea sindicato u otra- y ello, obviamente, supone la de la acción concertada como es la huelga. Sin embargo, no se dictaron normas especiales para prohibir estas organizaciones, sino que al considerarlas como atentatorias contra el orden público ${ }^{48} \mathrm{se}$ aplicaron las normas del Código Penal que sancionaba a las organizaciones cuyo fin era "turbar gravemente la tranquilidad pública" y "que se formasen con el

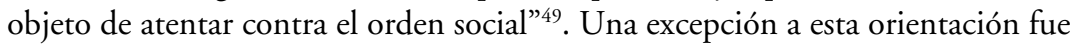
el reconocimiento jurídico de la Federación Obrera de Chile, FOCH, sindicato de carácter nacional al que se le otorgó personalidad jurídica en el año $1912^{50}$,

(Ley 1838 de 1906), Ley de descanso dominical para trabajadores del comercio (Ley 1990 de 1907, que estableció el derecho pero era de carácter renunciable y la Ley 3.321, de 1017, que estableció dicho descanso como de carácter irrenunciable), Ley de la Silla (Ley 2951 de 1914) Ley de Accidentes del Trabajo (Ley 3179 de 1916) y Ley de Salas Cunas (Ley 3186 de 1917)

${ }^{41}$ Hacia 1900 se logra la creación del Congreso social obrero, organización de carácter federativo que agrupa unas 169 sociedades de socorros mutuos (CETRA-CEAL, Cuadernos de Historia Popular, no 3, Santiago, s/f, p. 16).

${ }^{42}$ Los postulados centrales de estas organizaciones proclaman una abierta oposición al capital y sus hechos se orientan por este principio. De orientación anarquista, su presencia está condicionada a la duración del conflicto y una vez terminado éste tienden a desaparecer (CETRA-CEAL, ibíd.).

43 Organización que presenta rasgos de mutualismo y sindicalismo. Por una parte protege a sus asociados y fomenta la solidaridad obrera. Por la otra, organiza a los obreros y los defiende frente a los patrones (CETRA-CEAL, ibíd., p. 17).

${ }^{44}$ PiZArro, Crisóstomo, La huelga obrera en Chile (Santiago, Ediciones Sur, 1986), pp. 24 ss.

${ }^{45}$ La que comprende el período que va de 1879 a 1884.

${ }^{46}$ Ramírez N., Hernán, Historia del movimiento obrero en Chile, en Obras Escogidas (2a ed., Santiago, Ed. LOM, 2005), I, pp. 365 ss.

${ }^{47}$ Recuérdese al respecto la ley francesa Le Chapelier, de 1791.

${ }^{48}$ Como sostiene al efecto Poblete, Moisés, El Derecho del Trabajo y la Seguridad Social en Chile (Santiago, Editorial Jurídica de Chile, 1949), p. 61, se consideraban "como meros hechos de policía, que correspondían resolver a la autoridad policial”.

49 Artículos 269, 292, 293, 294 y 295 del Código Penal, vigente al año 1912.

50 Por Decreto Supremo 2.622 de 1912. 
es decir, hacia fines de esta primera etapa, hecho que ya plantea un cambio en la posición del Estado frente a la organización de trabajadores. Sin embargo, pocos años después se le quita dicho reconocimiento jurídico por una decisión administrativa $^{51}$, lo que muestra la sujeción del reconocimiento de estas organizaciones a una decisión de la autoridad política y administrativa. Relevante es plantear que la FOCH constituyó un sindicato, es decir una organización sindical simple, al que se afilia directamente el trabajador $^{52}$, por consiguiente fue un sindicato de carácter nacional y no una central sindical, como muchos lo han denominado ${ }^{53}$.

Hacia inicios del siglo veinte emerge la demanda de la intervención del Estado en la regulación de las relaciones laborales con el fin de establecer condiciones mínimas de trabajo y de retribución del mismo. Si bien los proyectos de leyes sociales aprobados en septiembre de 1924 tienen su origen inmediato en dos propuestas que emanan de las coaliciones de partidos políticos de esa época, la Alianza Liberal y el Partido Conservador, presentadas en los años 1921 y 1919, respectivamente, manifestándose de esta manera una preocupación por parte de un sector de estas entidades políticas respecto de las relaciones laborales y la cuestión social ${ }^{54}$, la que también se había presentado en las diversas leyes sobre materias laborales dictadas en el período ${ }^{55}$, además de la creación de la Oficina del Trabajo, antecesora de la Dirección del Trabajo, y las Comisiones Laborales creadas en el Congreso Nacional a partir del año 1907.

Por parte del movimiento de trabajadores son continuas las demandas de una legislación social presentadas desde el sector popular. Precisamente, el primer proyecto de ley sobre diversas materias de relaciones de trabajo es presentado por el Partido Democrático, que se le identifica como "el primer partido de raigambre netamente popular" ${ }^{56}$, a través de su líder, el diputado Malaquías Concha. Este proyecto de ley fue presentado en el año $1901^{57}$, y plantea regular materias básicas de las relaciones individuales del trabajo, las que fueron referidas básicamente al trabajo infantil, limitación del tiempo de trabajo, medidas ante la insalubridad e inseguridad en el trabajo e incorporación de normas de reparación ante los accidentes del trabajo.

En los años siguientes son presentadas por los sectores populares diversas propuestas de regulación de las relaciones laborales. Estas iniciativas plantean dos categorías

51 No es claro en qué año se le quita esta personalidad jurídica (en cuanto no se pudo obtener el decreto de supresión), sin embargo, es definitivo que al año 1925 ya no tiene tal existencia jurídica, toda vez que el Decreto Ley 575 de 2 de octubre de 1925, sobre reforma de la Ley que crea el Banco Central de Chile, plantea que la FOCH no tiene personalidad jurídica.

52 Como cita Barría, Jorge, cit. (n. 2), p.123, en su declaración inicial se plantea el ingreso directo de los trabajadores, carácter que mantiene la Convención de 1919, agregando que “[...] la agrupación básica seguirá siendo los Consejos, a base múltiple de obreros, empleados y artesanos de ambos sexos, que se organicen en cada pueblo [...]".

53 Es decir, una organización sindical que agrupa a otras organizaciones.

${ }^{54}$ YÁN̄EZ, Juan, cit. (n. 8) pp.1; GreZ, Sergio, cit, (n.8), pp. 1 ss.

55 Véase nota 40.

56 Grez, Sergio, cit. (n. 8), p. 2.

${ }^{57}$ Proyecto de Lei de Reglamentación del Trabajo, Presentado a la Cámara de Diputados en sesión de 26 de diciembre de 1901, por Malaquías Concha, en Boletín de la Sociedad de Fomento Fabril, año XX (Santiago, 1903), 1, pp. 23-25. 
de contenidos. En primer lugar, el ya referido a condiciones básicas de trabajo de la época, las que incluyen medidas respecto del trabajo infantil y de la limitación del tiempo de trabajo. En segundo término, sobre la indemnización por Accidentes del Trabajo, la que es demandada en los diversos sistemas jurídicos ${ }^{58}$, y que en el caso chileno constituye la reivindicación de legislación "que concitaba mayor adhesión en todo el país" ". Adicionalmente se planteó la demanda de establecimiento de entidades colegiadas que definieran condiciones mínimas de trabajo.

Sin embargo esta posición de demanda de la legislación laboral no fue unánime, toda vez que fundada en una gran desconfianza la corriente anarquista al interior del movimiento de trabajadores rechazó estas propuestas de legislación laboral ${ }^{60}$, como también lo planteó la tendencia 'doctrinaria' del Partido Democrático.

Frente a los proyectos de leyes sociales - del partido Conservador y de la Alianza Liberal- la FOCH efectuó propuestas sobre materias específicas. Así, durante el mes de enero de 1921 presento el proyecto relativo a "Cámara de Trabajo" ${ }^{61}$ y en febrero de 1921 el referido a "Contrato de Socialización Industrial"62.

Además, Luis Emilio Recabarren, dirigente de la FOCH y diputado de la Alianza Liberal, presentó un Proyecto sobre "Tribunal de Conciliación" ${ }^{63}$. El Proyecto de Socialización Industrial plantea un sistema de participación de los trabajadores tanto en la dirección de la empresa como en la distribución de los beneficios de la actividad empresarial, en una fórmula que hoy se denominaría d e c o g e s t i ó n. Mientras que el proyecto de Cámara del Trabajo y el de Tribunal de Conciliación, proponían crear organismos colegiados en cada provincia el país que tuvieran como objetivo definir condiciones comunes de trabajo ${ }^{64}$.Ciertamente que estas propuestas difieren del modelo que se estableció posteriormente y, además, no tuvieron acogida alguna en la discusión parlamentaria ${ }^{65}$.

\section{LAS LEYES SOCIALES y LA ESTRUCTURA SINDICAL}

Las Leyes Sociales de 1924 establecieron una regulación de las diversas materias de las relaciones laborales ${ }^{66}$. En un primer período estas leyes tuvieron una vigencia

\footnotetext{
${ }^{58}$ Sobre la responsabilidad empresarial por accidentes del trabajo y enfermedades profesionales, véase: NovoA, Patricio, Seguridad Social (Santiago, Ed. Jurídica de Chile, 1978), pp. 327-338.

${ }^{59}$ Así lo sostiene Grez, Sergio, cit. (n.8) p. 13, particularmente a partir de inicios de la segunda década del siglo 20, años cuando, además, se registra un aumento de accidentes del trabajo y una mayor sensibilización pública sobre el tema.

${ }^{60}$ Ibíd, p. 7.

${ }^{61}$ Citado por Mellado, Vicente, cit. (n. 13), p. 2.

62 Proyecto de Contrato de Socialización Industrial, publicado en el periódico El Despertar de los Trabajadores, Iquique, $1^{\circ}$ de marzo de 1921.

${ }^{63}$ Proyecto de Tribunal de Conciliación, publicado en el periódico La Gran Federación Obrera de Chile, Santiago, 7 de enero de 1921. Al respecto, PINTo, Julio, Luis Emilio Recabarren. Una bibliografía histórica (Santiago, Ed. LOM, 2013).

${ }^{64}$ Mellado, Vicente, cit. (n. 13), p. 3.

65 Ibíd.

${ }^{66}$ Ley No 4.053, sobre contrato de trabajo de obrero. Ley No 4.054, sobre seguro social obligatorio de enfermedad e invalidez. Ley No 4.055, sobre accidentes del trabajo. Ley No 4.056, sobre tribunales de conciliación y arbitraje. Ley No 4.057, sobre organizaciones sindi-
} 
irregular, la que es superada a partir de 1931, cuando tales textos legales, más sus modificaciones y la nueva normativa referida a materias laborales, se sistematizaron en el DFL No 1/1931, del Ministerio del Trabajo, constituyendo el primer Código del Trabajo vigente en Chile.

Las Leyes Sociales de 1924 y, posteriormente, el Código del Trabajo de 1931 acogieron un modelo normativo de relaciones laborales que plantean tres características fundamentales.

En primer término su fuente principal de regulación fue la ley, en cuanto las diversas áreas del ámbito laboral son reguladas por la ley, estableciendo de esta manera un sistema heterónomo de regulación de las relaciones de trabajo ${ }^{67}$.

En segundo lugar, dicho modelo tuvo un carácter protector del trabajador en las relaciones individuales de trabajo, al consagrar un conjunto de derechos en favor de éste y al ampliarlos progresivamente ${ }^{68}$. No obstante este mismo modelo legal no estuvo exento de críticas al discriminar entre dos categorías de trabajadores: los obreros y los empleados ${ }^{69}$, toda vez que en diversos aspectos la ley establecía un régimen jurídico diferente atendiendo a la categoría del trabajador.

En tercer término, la ley estableció una rígida regulación de las relaciones colectivas de trabajo, al definir el marco de organización y de acción de las asociaciones de trabajadores, además de limitar la titularidad de los derechos de sindicación. Sin embargo, la posición restrictiva de la ley no se plantea con igual intensidad en los otros institutos del Derecho Colectivo, como son la negociación colectiva y la huelga, los que si bien constituyen derechos de algunas organizaciones sindicales, respecto de ellos se establece una normativa flexible. De una parte, respecto de la negociación colectiva importaba el resultado, es decir el acuerdo colectivo, por lo que no estableció un procedimiento al efecto. De otra parte, el derecho de huelga se configuraba con ocasión del conflicto colectivo, una vez que se cumplía con las exigencias de conciliación. Cabe señalar que mayoritariamente la negociación colectiva se reconducía a través del proceso conflicto colectivo.

Respecto a la titularidad sindical,el modelo normativo de las Leyes Sociales de 1924 sólo permitió la sindicalización a los trabajadores del sector privado, en cuanto respecto del sindicato profesional, expresamente exceptuó a los emplea-

cales. Ley No 4.058, sobre sociedades cooperativas. Ley No 4.059, sobre contrato de trabajo de empleados particulares.

${ }^{67}$ Ello en contraposición a un sistema autónomo de regulación de las relaciones laborales, el que se presenta en sistema de alta autonomía colectiva.

${ }^{68}$ Ejemplo de ello es el sistema legal de terminación del contrato de trabajo, que de un sistema de libre terminación pasa a establecer beneficios económicos en favor del trabajador a través de la instauración de indemnizaciones por términos de contrato -aunque en muchos casos es discutible su carácter laboral o de seguridad social-, y, posteriormente, a fijar un sistema de estabilidad relativa en el empleo, con la Ley 16.455 de 1966.

69 El empleado era el que realizaba una labor "en la que predomina el esfuerzo intelectual sobre el físico" (art. 2. n.2 del C.T. 1931). Mientras que el obrero, por descarte, era quien realizaba una labor en la que predominaba el esfuerzo físico sobre el intelectual -aunque el texto legal utilizaba una redacción eufemística: “[...] toda persona que, sin estar comprendida en los números anteriores (es decir, patrón o empleador y empleado), trabaje por cuenta ajena en un oficio u obra de mano o preste un servicio material determinado-". 
dos públicos ${ }^{70}$, y si bien no se estableció una exclusión expresa en el ámbito del sindicato industrial, esta omisión fue salvada en la sistematización de estas Leyes Sociales efectuada a través del Código del Trabajo de 1931, en cuanto este nuevo texto estableció que "no podrán sindicalizarse ni pertenecer a Sindicato alguno, los empleados u obreros que presten sus servicios al Estado, a las Municipalidades o que pertenezcan a empresas fiscales." (Art. 365). Además sucesivas normas excluyeron a los trabajadores agrícolas del derecho de constituir organizaciones sindicales, lo que es superado con la entrada en vigencia de la Ley 16.625 de 1967.

A su vez, las mismas Leyes Sociales de 1924 definieron la estructura sindical al plantear que el sindicato se debía establecer en la base del sistema productivo, pudiendo constituirse dos tipos de sindicatos: el de empresa, denominado "industrial", y el profesional.

El sindicato industrial es el que se constituiría al interior de la empresa, con los trabajadores de la misma, sean obreros o empleados, siempre que estos últimos tuvieron un ingreso menor a una determinada cuantía. Respecto de ambas categorías de trabajadores su afiliación dependía de la vigencia del contrato de trabajo, en cuanto el término del contrato plantea la desafiliación del sindicato. Para constituir dicho sindicato se requería que la empresa tuviese más de veinticinco trabajadores y el acuerdo de a lo menos el 55 por ciento; a partir de la obtención de su personalidad jurídica, la afiliación era obligatoria para todos los trabajadores de la empresa.

Mientras que respecto del sindicato profesional la base de constitución era una misma actividad laboral o profesión ${ }^{71}$, por tanto su constitución era fuera de la empresa y, además, la afiliación al mismo era siempre voluntaria. En todo caso, la afiliación también depende de que el trabajador se mantenga en la respectiva industria que constituye la base de constitución del sindicato, en cuanto si deja de trabajar en ella por más de seis meses, se entenderá que deja de pertenecer a dicho sindicato ${ }^{72}$.

Además de la definición legal de la estructura sindical, la ley establecía los objetivos de estas organizaciones, en cuanto estas se concibieron como "[...] instituciones de colaboración mutua entre los factores que contribuyen a la producción y, por consiguiente, se considerarán contrarias al espiritu y normas de la ley, las organizaciones cuyos procedimientos entraban la disciplina y el orden en el trabajo"73, aunque sí se les reconoció el derecho de negociación colectiva, entre otros. Además, respecto del sindicato industrial estableció una forma especial de financiamiento a través de la participación en una parte de las utilidades de la empresa.

Asimismo la ley estableció medidas de control del Estado referidas a la ob-

\footnotetext{
${ }^{70} \mathrm{Al}$ efecto, el Artículo 23 inciso primero de la Ley 4057 establecía que "los empleados públicos no podrán organizarse en sindicatos en conformidad al presente título".

${ }^{71} \mathrm{O}$, como prescribía el texto legal, "[...] una misma profesión, industria o trabajo, o profesiones, industrias o trabajos similares o conexos [...]” (art. 410 del C.T. de 1931).

72 Art. 32 de Ley 4057.

73 Así lo sintetiza el Art. 364 del D.F.L. 178 de 1931, en cuanto establece una norma genérica para ambos tipos de sindicatos.
} 
tención de la personalidad jurídica ${ }^{74}$, de diversas actuaciones del sindicato $^{75} \mathrm{y}$ de su disolución ${ }^{76}$. Sin embargo en la Ley 4.057 estas medidas están referidas sólo al sindicato profesional, y posteriormente, a través de específicos textos normativos posteriores, como fueron son el Decreto 2148 de 1928, del Ministerio de Bienestar, y el Código del Trabajo de 1931, se amplían al sindicato industrial.

Si bien, los sindicatos tanto industriales de empresa como profesionales podían constituir organizaciones de segundo nivel, uniones o confederaciones sindicales, únicamente se reconoció titularidad para negociar colectivamente a la confederación de sindicatos profesionales y no a la de sindicatos industriales, toda vez que por mandato legal "sólo se permitirán las reuniones o confederaciones de sindicatos industriales para fines de educación, asistencia previsión y para el establecimiento de economatos y cooperativas"77.

\section{EL ORIGEN DEL MODELO SINDICAL: DOS PROYECTOS} IDEOLÓGICOS DIVERSOS

Si bien es un hecho conocido, poco se recuerda que la regulación de algunas materias de las Leyes Sociales de 1924 tuvo su origen en dos proyectos de ley, presentados por entidades políticas distintas y con fundamentación diversa: uno es la propuesta del Partido Conservador y otro la propuesta de la Alianza Liberal ${ }^{78}$. Precisamente, la normativa sobre organización sindical tuvo su origen en ambos proyectos.

La propuesta del Partido Conservador fue presentada ante el Senado en el mes de junio de 1919, por un grupo de siete senadores ${ }^{79}$. Las materias que proponía regular eran limitadas, toda vez que estaban referidas, de una parte, a específicas materias de protección en el ámbito de las relaciones individuales de trabajo ${ }^{80} \mathrm{y}$, de la otra, al reconocimiento de un tipo de sindicato, el de empresa, y a la conciliación obligatoria de los conflictos colectivos.

Mientras que la propuesta de la Alianza Liberal, presentada por el presidente de la República, Arturo Alessandri Palma, en el año $1921^{81}$ en la modalidad de un

${ }^{74}$ Dado que el otorgamiento de la personalidad jurídico era decisión del Ejecutivo, ante quien se presentaba la respectiva solicitud, a través de la Dirección General del Trabajo, previo cumplimiento de las exigencias señaladas en la ley (Art. 26 de Ley 4057).

${ }^{75}$ En cuanto las reformas del estatuto sólo serán válidas con aprobación previa del Ejecutivo. Asimismo, el sindicato debe comunicar "mensualmente" a la Dirección del Trabajo los cambios referidos a "el número y nacionalidad de los socios, con especificación de la profesión o profesiones que ejerzan [...]", y también deberán enviar a dicha Dirección "[...] una vez al año, por lo menos, un nómina con los nombre, profesión y nacionalidad de los miembros, los balances y memorias y los demás datos y documentos que determinen los reglamentos respectivos". Art. 36 de Ley 4.057 .

76 Toda vez que la disolución de las asociaciones profesionales deberá ser decretada especialmente por el Presidente de la República, de acuerdo a exigencias y procedimientos que se establecen (Art. 42 de Ley 4.057).

77 Art. 386 C.T. de 1931.

${ }^{78}$ Los fundamentos ideológicos de ambas propuestas han sido estudiadas latamente por Morris, James, cit. (n. 9), pp. 109-175.

79 Proyecto del Partido Conservador, en Acta del Senado, Ordinaria, 1919, pp. 40 ss.

${ }^{80}$ Como eran el trabajo de menores, de las mujeres, salario mínimo y jornada máxima de trabajo.

${ }^{81}$ Proyecto de Alianza Liberal Actas de Cámara de Diputados, Ord. 1921, pp. 63 ss. 
Código del Trabajo, proponía la regulación de las diversas materias de las relaciones laborales, tanto de las relaciones individuales como colectivas de trabajo y, además, materias de seguridad social, como son el seguro obrero y el régimen de accidentes del trabajo ${ }^{82}$. Respecto a la organización de trabajadores propone el reconocimiento del sindicato profesional, es decir la asociación de trabajadores en razón de su oficio y, por tanto, independientemente de la empresa; además la afiliación y la conciliación tendrían carácter voluntario, pudiéndose constituir además organizaciones sindicales superiores, tales eran la federación y confederación sindical. Sin embargo, este mismo proyecto planteaba un fuerte control desde el Estado respecto de las organizaciones sindicales en las materias ya señaladas de la obtención de la personalidad jurídica ${ }^{83}$, de diversas actuaciones del sindicato ${ }^{84} \mathrm{y}$ de su disolución ${ }^{85}$; en términos más estrictos de los que posteriormente fueron aprobados y promulgados en la Ley $4.057^{86}$.

Considerando la ideología de estos partidos políticos es posible entender medianamente su propuesta sindical.

La del Partido Conservador limitaba la actuación organizada de los trabajadores en el nivel de empresa a través del sindicato industrial de empresa excluyendo la existencia de federaciones ni confederaciones sindicales. Si bien esta propuesta no fue fundamentada en cada uno de las materias que plantea regular, el proyecto planteado da cuenta de dos antecedentes. El proyecto en general se fundamenta en el requerimiento de proteger a los trabajadores y generar relaciones tendientes a la paz y armonía industrial ${ }^{87}$. Mientras que la propuesta sindical se plantea directamente el objetivo de e n c a u z a r su establecimiento, es decir su modo de organización y de actuación ${ }^{88}$, y ello "[...] a fin de que en su ejercicio no se desnaturalice su objeto y que, en vez de ser un factor de progreso y de orden, se convierta en una ola de orden y anarquía" 89 .

${ }^{82}$ En este sentido, se propone un Proyecto de Código del Trabajo y de Previsión Social - Proyecto de Código del Trabajo y de la Previsión Social, en Actas de Cámara de Diputados, Ord. 1921, Sesión 2a, 4 de junio de1921. Anexo, p. 9-, el que comprende 620 artículos, organizados en cuatro libros: Primero, de las convenciones relativas al trabajo. Segundo, de la reglamentación del trabajo, Tercero, de las asociaciones profesionales y del conflicto del trabajo. Cuarto, de la previsión social.

${ }^{83}$ Art. 288 del Proyecto del Código del Trabajo presentado, ibíd.

${ }^{84}$ Art. 318 del Proyecto del Código del Trabajo presentado, ibíd.

${ }^{85}$ Art. 319 del Proyecto del Código del Trabajo presentado, ibíd..

${ }^{86}$ En efecto, a vía de ejemplo, en el procedimiento de obtención de la personalidad jurídica se establece que "[...] sin perjuicio de la facultad del Gobierno para requerir previamente de la asociación solicitante, la reforma de estatutos o la rectificación de hecho y declaraciones que se estimen necesarias [...]". Art. 288, Proyecto, ibíd.

${ }^{87}$ Como señala el Proyecto del Partido Conservador, cit. (n. 79), p. 40, "Hace tiempo se viene haciendo notar la necesidad de una legislación social del trabajo que, a la vez de proteger y amparar la condición de los obreros, coopere al estrechamiento de sus relaciones con los patrones y capitalistas, para producir la paz y la armonía industriales, bases fundamentales del orden, del progreso y del bienestar del pueblo".

88 "Este movimiento universal, innegable, que parte de un principio lícito, como es el derecho de asociarse para defender los intereses de trabajo en el régimen del mismo, no solo es necesario reconocer su existencia y su licitud, sino que es preciso encauzarlo [...]". Proyecto de Partido Conservador, cit. (n. 79), p. 41.

${ }^{89}$ Ibíd. 
Por consiguiente, la propuesta del sindicato de empresa acoge la idea de mantención del orden que propone el Partido Conservador, pero ¿por qué esta actuación sindical debe restringirse al ámbito de la empresa? La respuesta es posible deducirla de la argumentación vertida en la Comisión Mixta generada para la discusión de los proyectos de leyes sociales, y que fuera expuesta principalmente por quien reconoce ser el autor de dicho Proyecto, el entonces Senador del partido Conservador Juan Enrique Concha, quien plantea que la acción sindical se debe circunscribir a la empresa, en cuanto es esta organización la que garantiza la supuesta armonía entre el trabajo y el capital, ya que "el proyecto en su conjunto inspiraba orden y armonía, porque se basaba en el concepto de la solidaridad entre el trabajo y el capital" ${ }^{\circ}$. Además, es posible que hayan concurrido otras motivaciones en la fijación de esta estructura del proyecto del Partido Conservador. Como señala Morris ${ }^{91}$, la elite rural era la base principal de la aristocracia católica del Partido Conservador, y ésta difícilmente habría aceptado la acción sindical fuera de hacienda, tanto el tipo de relación casi semifeudal entre hacendados y campesinos como por su negativa a interactuar con dirigentes provenientes de otros ámbitos.

Por su parte, el proyecto de la Alianza Liberal, planteaba el sindicato profesional y la libre afiliación. Su fundamentación era clara, en cuanto la propuesta respondía al concepto de "verdadero sindicalismo" de quienes lo presentan, y que corresponde al sindicato gremial o profesional que se limita "... a la mejora de las condiciones de trabajo" y ello en contraposición al "[...] sindicalismo revolucionario, que no es más que una falsificación o una corrupción de aquée', tal como expone el Proyecto de Código del Trabajo y Previsión Social presentado por el entonces presidente Arturo Alessandri ${ }^{92}$. Si bien esta propuesta se basó en un modelo normativo europeo, específicamente en la Ley francesa Waldeck-Rousseau, de $1884^{93}$, en contradicción a dicha ley, proponía una intervención estatal tanto en la constitución como en la acción y disolución del sindicato. Si bien es posible entender desde la perspectiva liberal tanto la afiliación como la conciliación voluntaria, no es clara la opción de la estructura sindical, dada las diversas opciones que ya mostraba el derecho comparado, como es el sindicato cuya base la determinasen los mismos trabajadores o que, al menos, estuviese definida fuera de la empresa.

Es cierto que en la Alianza Liberal se planteaban diversas posiciones, siendo minoritarias las que aceptaban plenamente a la organización de los trabajadores, como fue la del diputado radical Santiago Labarca, respecto de quien se señala sostener que “[...] la estructura sindical debía corresponder a la expresión del verdadero sentir de las masas y facilitarla. El sindicalismo de lucha de clases, que él identificaba con los principios del profesionalismo sindical, habría de ser en su opinión, más realista que la solidaridad entre el capital y el trabajo" ${ }^{4}$.

Si bien el autor del Proyecto definitivo fue Moisés Poblete Troncoso, tal como

90 Morris, James, cit. (n.9), p. 190.

${ }^{91}$ Ibíd., p. 123.

${ }_{92}$ Proyecto de Código del Trabajo, cit. (n. 82).

${ }^{93}$ La que reconoció el derecho de asociación profesional, constituyendo la primera normativa destinada a superar la prohibición del sindicato, impuesto por la Ley Chapelier, de 1791.

${ }^{94}$ Morris, James, cit. (n.9), p. 190. 
lo reconoce el Presidente Arturo Alessandri en carta enviada desde el exilio en el año $1929^{95}$, varios de los partidos que integraban dicha coalición presentaron propuestas previas, las que iban desde establecer un sistema de libre afiliación, con predominio del ideario liberal, hasta la de desconocer eficacia a la legislación social ${ }^{96}$. Esta diversidad de posiciones permitiría entender la propuesta planteada por el Partido Liberal, organizaciones de trabajadores por oficio y con libertad de afiliación, pero, a la vez, un fuerte poder del Estado sobre dichas organizaciones.

\section{LA APROBACIÓN Y POSTERIOR APLICACIÓN DE LA LEY SINDICAL}

Lo que sucedió con posterioridad es historia conocida. Existiendo dos propuestas en las materias de contrato de trabajo y de sindicato, la Cámara de Diputados y el senado acordaron constituir una Comisión Mixta de Legislación Social ${ }^{97}$. Primero fue despachado el proyecto de contrato de trabajo ${ }^{98} \mathrm{y}$, con posterioridad, el 6 de junio de 1923, la Comisión Mixta presentó ante la Cámara de Diputados la propuesta referida a organización sindical ${ }^{99}$.

En esta propuesta se acogen ambas modalidades de sindicatos, fundado en que "dentro del mecanismo establecido en el proyecto de la Comisión, ambas organizaciones pueden formarse y subsistir conjuntamente: el sindicato industrial, dentro de la fábrica o empresa, y el profesional, fuera de ella" ${ }^{100}$. Por consiguiente, la propuesta plantea la coexistencia del sindicato industrial de empresa con afiliación obligatoria y el sindicato profesional de libre afiliación, pero con una modificación de la propuesta original del Partido Conservador, y es que la Comisión Mixta admite la existencia de uniones y confederaciones de sindicatos de empresa, aunque sólo tendrán fines de "asistencia sanitaria, de retiro obrero y constitución de cooperativas"101, por lo que se excluye su titularidad para negociar acuerdos colectivos; derecho que sí se reconoció a las organizaciones superiores de los sindicatos profesionales ${ }^{102}$. En todo

95 Así se expresa en carta que el entonces ex presidente D. Arturo Alessandri Palma envía desde el exilio a Moisés Poblete Troncoso y que está fechada en París, a 30 de noviembre de 1929, en Poblete, Moisés, El Derecho del Trabajo y la Seguridad Social en Chile (Santiago, Editorial Jurídica, 1949) pp. 18-27.

${ }^{96}$ En este sentido Enrique Mac Iver, creía que "dado el carácter inferior de los trabajadores chilenos, la legislación no serviría de nada”. Morris, James, cit. (n. 9), p.135.

${ }^{97}$ Acuerdo sobre generación de Comisión Mixta, véase: (1) Acta de Cámara de Diputados, Extraordinaria, 1921.22, p. 640, sesión 20, y pp. 687 a 691. Sesión 22, 30 de noviembre y 1 de diciembre de 192, se acuerda invitar al Senado a nombrar una Comisión Mixta para que estudie los Proyectos sobre Legislación Social. (2) Acta de Senado, Extraordinaria, 1921-22, pp. 552-553, sesión 41, se acepta invitación del a Cámara de Diputados.

${ }^{98}$ El Informe del Proyecto del Contrato de trabajo fue efectuada el 29 de julio de 1922, en presentación en sesión de 6 de junio de 1923. Acta de Cámara de Diputados, 1923, Ordinaria, pp. 48, Sesión 2.

99 Informe de Comisión Mixta, Acta de Cámara de Diputados, 1923, Ordinaria, pp.4854 , Sesión 2.

100 Ibíd., p. 48.

101 Art. 14 de Informe de Comisión Mixta de Legislación Social, cit. (n. 99), p. 50.

102 Artículos 36 y 37 de Informe de Comisión Mixta de Legislación Social, cit. (n. 99), pp.52-53. 
caso, dicha propuesta extendió el control del Estado a ambos tipos de sindicatos, tanto en lo que se refiere a su constitución como su funcionamiento y disolución.

Con posterioridad, en septiembre de 1924, irrumpió en el Congreso Nacional un grupo de oficiales del ejército a expresar su malestar por el retardo en el despacho de proyectos destinados a solucionar sus problemas salariales y presentaron al Presidente Alessandri un memorándum con una serie de peticiones, entre ellas la aprobación de las leyes sociales. Esta acción llevó a que días más tarde el Ministro del Interior, en nombre del Presidente de la República, solicitara ante la Cámara de Diputados y el Senado la inmediata aprobación de varios proyectos, entre ellos las leyes sociales, lo que el Congreso acordó en esa misma oportunidad, entre ellas la Ley 4.057 sobre "organización sindical".

Pocos años después se dictó el Reglamento para la aplicación de la Ley 4.057, a través del Decreto 2148 de 1928 del Ministerio de Bienestar, que entre otras materias planteó "establecer normas de control con el fin de hacer más eficiente el cumplimiento de la ley [...]". Precisamente entre estas normas de control, y a fin de "impedir la desviación de las finalidades de orden y de disciplina de los Sindicatos [...]”, las autoridades de las Secretarías de Bienestar Social podrán por sí o por los funcionarios que designen "[...] presidir las reuniones de los Sindicatos y conocer sus actas, documentos, administración económica y todas las actividades que desarrollen [...]" (art. 7, inciso $1^{\circ}$, Decreto 2148)

Son las leyes sociales ${ }^{103}$ más algunas modificaciones planteadas en los años siguientes, incluida la creación de los Tribunales del Trabajo a través del D.L. 2.100 de 1927, fueron sistematizadas en un texto único, el D.F.L. 178 de 1931, generando el Código del trabajo de ese mismo año.

\section{El imPaCto DEL MODELO SINDICAL DE LAS LEYES SOCIALES EN EL SISTEMA DE RELACIONES LABORALES}

La nueva institucionalidad laboral establecida por las Leyes Sociales de 1924 tardó en ser aplicada y hubo diversas posiciones de los trabajadores respecto de la misma, diferencias que se manifestaron particularmente respecto de la ley sobre organización sindical, respecto de la cual la posición fue en general de rechazo, aunque en la actualidad se discute los niveles de oposición a esta institucionalidad sindical ${ }^{104}$. A la fecha de aprobación de esta legislación las organizaciones principales eran la Federación Obrera de Chile, FOCH, y la de "Trabajadores Industriales del Mundo” IWW, quienes rechazaron esta normativa sindical y, por consiguiente, permanecieron como sindicatos de hecho. Sin embargo, un sector de la FOCH percibió en esta legislación la posibilidad de extender su influencia a sectores en que el

${ }^{103}$ Que fueron las siguientes: Ley 4.053 sobre contrato de trabajo obrero; Ley 4.054 sobre seguro social obligatorio; Ley 4.055, de indemnización por accidentes del trabajo; Ley 4.056, de tribunales de conciliación y arbitraje; Ley 4.057 sobre sindicatos profesionales; Ley 4.058, sobre cooperativas y Ley 4.059, sobre contrato de trabajo de empleados particulares.

104 Sobre la materia véase RoJAS, Jorge, La dictadura de Ibáñez y los sindicatos (1927-1931) (Santiago, Ed. Universitaria, Colección Sociedad y Cultura, 1993) y Mellado, Vicente, cit. (n. 8), pp. 85-125. 
sindicalismo era débil o inexistente ${ }^{105}$, por lo que posteriormente sí se constituyeron como sindicatos legales. Durante el régimen dictatorial del General Ibáñez, de 1927 a 1931, se implementan diversas medidas para la aplicación de la legislación sindical ${ }^{106}$, incluida la coacción ${ }^{107}$.

Si bien la conformación del Frente Popular en el año 1936 planteó que los sindicatos legales y los de hecho se reconocieran mutuamente, la aceptación del modelo normativo en términos generales sólo se planteó al asumir como Presidente de la República Pedro Aguirre Cerda. Es entonces que “...por primera vez el sindicalismo legal se desprende de la general confusión, sospechas y hostilidad que lo postergaron durante más de una década, progresando rápidamente, para convertirse, numéricamente, en el alma y centro del movimiento obrero" ${ }^{\prime 108}$.

Sin embargo, los resultados de la aplicación de este modelo muestran la afiliación sindical fue limitada y en dicho marco resultó privilegiado el sindicato industrial de empresa. Así, en el período de vigencia de dicho modelo normativo, que para efectos de su estudio se extiende hasta el año 1964, dado los cambios normativos que se introducen a partir de esa fecha ${ }^{109}$, la relevancia del sindicato industrial de empresa en ese sistema de relaciones laborales llevó a afirmar que éste "constituye (n) la espina dorsal del movimiento sindical y de la estructura del sistema de relaciones industriales y laborales del país al existir uno por cada empresa local en que se reúnan los requisitos legales para formarlo"110.

En el año 1964 sólo el 17,5\% de los trabajadores dependientes del sector privado estuvieran sindicalizados ${ }^{111}$. De estos trabajadores un 53,2\% estaba afiliado a sindicatos industriales y cada uno de éstos que tenían un promedio de 230 trabajadores (se trataba de 148.364 trabajadores en 644 sindicatos industriales), el 46,2\% estaba afiliado a sindicatos profesionales, los que tenían en promedio 104 trabajadores (128.960 trabajadores en 1236 sindicatos profesionales) y un $0,6 \%$ en sindicatos agrícola con un promedio era de 68 trabajadores ${ }^{112}$.

105 Morris, James, cit. (n. 9) p. 207.

${ }^{106} \mathrm{Al}$ respecto, véase RoJAs, Jorge, cit. (n. 104), pp. 61-75.

107 Pero la solución fue la extremar aún más el control desde el Estado, para lo cual se dictó el Reglamento ya citado para la aplicación de la ley sindical: el Decreto 2148 de 1928.

108 Morris, James, cit. (n. 9) p. 217.

109 En los años siguientes, de 1964 a 1973, no hubo una modificación profunda del modelo normativo de relaciones colectivas de trabajo, pero sí reformas en determinadas áreas del sistema de relaciones industriales, como fueron las planteadas por la ley de sindicación campesina (Ley 16.625, de 1967), la ley sobre comisiones tripartitas (Ley 17.074, de 1968) y la ley que otorgó 'personalidad jurídica a la central sindical, es decir, la Central Única de Trabajadores, CUT (Ley 17.594, de 1972), aunque esta última ley estableció las bases normativas sobre otras materias sindicales, como fueron la obtención de personalidad jurídica por parte de las organizaciones sindicales por el sólo depósito de los estatutos y el acta constitutiva en la respectiva Inspección del Trabajo y la generación democrática de sus directivas, garantizada entre otras medidas a través de la elección directa por todas las bases sindicales.

110 BARRÍA, Jorge, (1967), Las Relaciones Colectivas del Trabajo en Chile (Santiago, INSORA, Instituto de administración, Universidad de Chile, s/e.), p. 48.

111 Derto, Departamento de Relaciones de Trabajo y Desarrollo Organizacional, Universidad de Chile, Estadísticas Sindicales 1956-1972, (Santiago de Chile, s/e), p. 21.

112 Ibíd. 
La prevalencia del sindicato industrial también se manifestaba en una de las principales acciones del sindicato y que es la negociación colectiva, en cuanto dicha actividad era sostenida principalmente por el sindicato industrial. En efecto, en ese año 1964 de los 1.110 pliegos de peticiones que se presentaron y que cubrieron a 203.406 trabajadores asalariados ${ }^{113}$ y siendo el sujeto laboral un sindicato en el $89 \%$ de los casos (toda vez que la representación a través de una organización transitoria -11\%- sólo se permitía en el supuesto de que no existiera sindicato); la negociación tuvo como sujeto laboral a un sindicato industrial en un 75,6 de los casos. Además, la casi totalidad de sindicatos industriales negociaba colectivamente, toda vez que existiendo al año 1964 un número de 644 sindicatos industriales, un total de 525 negocia por la vía legal del planteamiento de un conflicto colectivo y 69 por otras vías.

Ciertamente que esta posición privilegiada no está exenta de cuestionamientos, al excluir, o no integrar, a la mayoría de los trabajadores asalariados. En primer lugar, el sindicato industrial de empresa sólo existía en los sectores más dinámicos de la economía y, al interior de éstos, en las empresas medianas y grandes. En efecto, el sindicato industrial se concentró en un $90 \%$ en las actividades industriales y de la minería ${ }^{114}$, en circunstancias de que ambos sectores sólo representaba al 32,6\% de los trabajadores ocupados. A la vez, no significó que organizaren a todos los trabajadores de estos sectores: sólo a un $55,7 \%$ de la minería y a un 31,6\% de la industria. Por consiguiente el sindicato industrial de empresa no tuvo implantación en las demás actividades económicas y tampoco en las empresas pequeñas de la industrial ni de la minería.

Ciertamente que estos resultados sugieren diversas interrogantes, como es la referida a la negociación colectiva por vía del sindicato profesional, en cuanto sólo un $25 \%$ de los trabajadores organizados en este tipo de sindicatos negociaba colectivamente. Asimismo, también fue limitada la negociación por vía de las organizaciones sindicales superiores, como era la confederación sindical ${ }^{115}$.

En todo caso, en este período hubo una tendencia a la unión de los sindicatos en entidades de carácter superior, ya que se afiliaron a federaciones y confederaciones sindicales, y los distintos tipos de entidades laborales se afiliaron en organizaciones superiores de nivel nacional, tal como fueron la Confederación de Trabajadores de Chile, CTCH -en el período 1936 a $1946^{116}$ - y, posteriormente, la Central

113 BARRÍA, Jorge, Las relaciones colectivas (1967), cit. (n. 110), pp. 46-47.

${ }^{114}$ Derto, cit. (n.111), cuadro 20i. s.p. Al efecto, debe recordarse que la minería fue desde fines del siglo 19 uno de los sectores más dinámicos de la economía chilena, entonces con la explotación del salitre y posteriormente con la producción del cobre, el que, hacia la fecha que consideramos (1964), estaba explotado por capitales extranjeros; solo en 1966 el Estado de Chile adquiere la parte mayoritaria de su propiedad a través del proceso de c h i l e n i z a c i ó n del cobre y ya en 1971 su propiedad total con la n a c i o n a li z a c i ó n del cobre. La industria por su parte, había tenido desde el Estado un impulso para su desarrollo, a partir del proceso de "sustitución de importaciones" dirigido desde la Corporación de Fomento hacia fines de la década del treinta.

${ }^{115}$ De alguna manera, estas interrogantes han sido planteadas en diversos trabajos. Por todos, Rojas, Irene, cit. (n. 23), pp. 73-108.

${ }^{116}$ En el año 1946 la CTCH se divide en dos fracciones, las que posteriormente se suman a la siguiente organización sindical de carácter nacional, la Central Única de Trabajadores, CUT. 
Unitaria de Trabajadores, CUT -en el lapso de 1953 a 1973-. Sin embargo, la función de estas últimas entidades era la de la representación de los intereses de los trabajadores en el ámbito nacional y no en el de las relaciones colectivas de empresa y de sector económico.

\section{CONCLUSIONES}

En este trabajo se plantearon dos interrogantes respecto del modelo sindical establecido en las Leyes Sociales de 1924.En primer lugar, por qué dicho modelo definió una estructura sindical y, en dicho marco, por qué estableció los dos tipos de sindicatos señalados: el industrial de empresa y el profesional. En segundo lugar, qué consecuencias tuvo esta definición normativa en el sistema de relaciones laborales, en especial respecto de los niveles de sindicalización y de acción colectiva.

Respecto de la primera pregunta, el antecedente inmediato es que la estructura sindical definida en dicho modelo normativo respondió a dos proyectos de ley presentados, a su vez, por cada una de las entidades políticas con representación parlamentaria en dicho período, el partido Conservador y la Alianza Liberal. Cada uno de estos proyectos definía un tipo de sindicato, los que se suman en la propuesta de la Comisión Mixta que se definió para dichos efectos al interior del Congreso Nacional, con el argumento de que "ambas organizaciones pueden formarse y subsistir conjuntamente" ${ }^{117}$. Si bien cada uno de las propuestas fundamenta el tipo de sindicato que propone, ninguna de ellas da cuenta de la intervención legal en la definición de una específica estructura sindical.

Así, como primera conclusión se advierte que la intervención del Estado en materia sindical fue asumida por el legislador sin cuestionar tal facultad, en circunstancias que no se trataba de reconocer el derecho de sindicación en términos amplios y, menos aún, el de establecer los instrumentos para garantizar el ejercicio de tal derecho, sino que tenía como objetivo definir la estructura sindical y los sectores de trabajadores a quienes se le reconocía tal derecho, además de establecer la sujeción de los sindicatos al control del Estado. Asimismo, el legislador tampoco cuestionó la contradicción de dicha normativa con principios superiores, tal como es el de libertad sindical, el que si bien no había tenido mayor desarrollo, sí estaba contemplado en la Constitución de la OIT, entidad a la cual se había incorporado el Estado de Chile desde su creación en el año 1919.

Podría señalarse, en contrario, que en otros sistemas sí se dictaron leyes en tal sentido. Si bien ello es cierto, habría que analizar el período y el contexto en que se dictaron dichas regulaciones ${ }^{118} \mathrm{y}$, además, que tal normativa también puede ser objeto de la misma crítica que se formula al modelo sindical de las leyes sociales de 1924.

También podría sostenerse que el movimiento de trabajadores había demandado desde inicios del siglo veinte la intervención legal del Estado en las relaciones

117 Informe de Comisión Mixta (1923), cit. (n. 99).

118 Es por ello que debe excluirse de tal crítica a la ley francesa Waldeck-Rousseau, que estableció el sindicato profesional en Francia, en cuanto había sido dictada treinta años antes de las leyes sociales de 1924. 
laborales, lo que se manifiesta en diversas propuestas, incluidas las que presentó la FOCH en el período de discusión de los proyectos que anteceden a las leyes sociales referidas. Ello es cierto, pera esta demanda se limitaba a las condiciones de trabajo y, por tanto, estaban referidas al área de las relaciones individuales de trabajo. En tal sentido, la única propuesta en el ámbito de las relaciones colectivas estuvo referida al establecimiento de entidades para la fijación de condiciones mínimas. Por consiguiente nunca hubo una demanda de intervención en las organizaciones de los trabajadores. Precisamente, uno de los debates que se planteó entre las entidades sindicales con posterioridad a las dictación de las leyes sociales de 1924 es que si se acogerían o no a dicha regulación, lo que sí hicieron algunas de ellas, y que tiene como efecto la existencia de los sindicatos legales y los de hecho por un período cercano a diez años, hasta que finalmente se admitió el modelo sindical, momento que coincide con el inicio del Frente Popular en el año 1936.

La segunda conclusión es que cada una de las propuestas y, tras de ellas, cada una de las entidades políticas que la presenta, define la forma en que deben organizarse los trabajadores: en la empresa por parte del Partido Conservador y a través del sindicato profesional por parte de la Alianza Liberal -aunque en esta entidad hubo otras posiciones, pero fueron marginadas ${ }^{119}$-. La primera propuesta, la del Partido Conservador, plantea que la ley debe "encauzar" dicha forma de organización tras el objetivo de "generar relaciones tendientes a la paz y armonía industrial" ${ }^{120}$. Mientras que la segunda propuesta, la de la Alianza Liberal, plantea que el sindicato profesional, constituye el verdadero sindicalismo, en cuanto se limita "a la mejora de las condiciones de trabajo". La admisión por parte de la Comisión Mixta de ambos tipos de sindicatos fue tarea fácil, en cuanto ambas propuestas se basaban en el reconocimiento de un limitado espacio para el sindicato: como "instituciones de colaboración mutua entre los factores que contribuyen a la producción" ${ }^{121}$, lo que, a su vez, se funda en el rechazo al conflicto laboral yal sindicalismo que reivindica más allá de las condiciones de trabajo.

Respecto de la segunda interrogante -qué consecuencias tuvo esta definición normativa en el sistema de relaciones laborales, en especial respecto de los niveles de sindicalización y de acción colectiva-, lo cierto es que el análisis debería incorporar los demás antecedentes que definen un sistema de relaciones laborales, como son los económicos y sociales. No obstante, el dato cierto, de acuerdo con la información referida ${ }^{122}$, al año 1964 sólo el $17 \%$ de la población laboral dependiente del sector privado estaba sindicalizada ${ }^{123}$. Además, se concluye que el sindicato privilegiado por el sistema fue el industrial de empresa, tal como ya se planteó

119 En este sentido, debe recordarse que al interior de la Alianza Liberal el Diputado de dicha coalición Santiago Labarca planteaba "que la estructura sindical debía corresponder a la expresión del verdadero sentir de lasa masas y facilitarla". Al efecto, véase sección IV, sobre "el origen del modelo sindical: dos proyectos ideológicos diversos”, en especial véase cita n. 94 .

120 Ibíd.

121 Tal como lo declaró el citado Art. 364 del D.F.L. 178 de 1931, cit. (n. 73).

122 DERTO (1977), cit. (n. 111).

123 Ibíd. 
en la década de los años sesenta del siglo veinte ${ }^{124}$, y que el sindicato profesional tuvo escaso espacio para su desarrollo. Así las cosas, el desarrollo del sindicalismo bajo ese modelo estaba limitado y no podía seguir creciendo, toda vez que existía el sindicato industrial en todas las empresas en donde podía constituirse ${ }^{125}$.

Por su parte, la cobertura de la negociación colectiva también fue limitada, en cuanto se concentró en la realizada por los sindicatos industriales de empresa en el $75 \%$ de los casos. Así la intervención legislativa limitó la negociación colectiva a través de dos vías: por las restricciones impuestas al sujeto laboral, al negar el derecho de sindicación a algunos sectores de trabajadores y, además, por la limitación de la titularidad de la negociación colectiva a organizaciones sindicales superiores como eran la federación y confederación de sindicatos industriales, resultando privilegiado el sindicato de empresa.

En una perspectiva actual, el análisis del modelo sindical de las Leyes Sociales de 1924 concluye necesariamente en su contradicción general con el principio de libertad sindical y de los derechos que la integran, particularmente por la definición legal de la estructura sindical y su establecimiento en la base del sistema productivo, además de la sujeción a la intervención y control estatal. Ciertamente que esta crítica puede atenuarse en atención al período histórico en que se gestó dicho modelo. Sus orígenes se remontan a las primeras décadas del siglo 20, constituye la primera definición normativa de las organizaciones de trabajadores. No obstante, no debe olvidarse la intencionalidad política en la fijación de este marco sindical y que originó, como señaló Morris en la década de los años sesenta, ciertas “[...] prácticas, estructuras y moldes de conducta en el campo de las relaciones de trabajo en la actualidad chilena, que muy difícilmente podrían llegar a comprenderse [...]"126, como es la importancia del sindicato de empresa.

De este estudio surgen dos reflexiones que proponen diversas hipótesis de trabajo, las que permitirán continuar con este análisis en futuras publicaciones.

Una primera reflexión es la referida a la incidencia del modelo normativo del sindicato definido en las leyes sociales de 1924, la que no se limitaría al sistema de relaciones laborales del período de vigencia del antiguo Código del Trabajo de 1931, sino que llegaría hasta nuestros días. En efecto, el sindicato de empresa sigue siendo el mayoritario en el conjunto de la afiliación sindical, ocupando un espacio que representa un $70 \%$ del total de trabajadores afiliados y el $63 \%$ de los sindicatos existentes ${ }^{127}$, constituyéndose en promedio como un sindicato de un tamaño pequeño, en cuanto sólo comprende 99 trabajadores por sindicato ${ }^{128}$. Cierto es que para medir tal concurrencia, debería también analizarse otros aspectos que colaboran con esta relevancia del sindicato de empresa, como son,

124 Barría, Jorge, cit. (n. 110).

125 Ibíd.

${ }^{126}$ Morris, James, cit. (n. 9), p 11.

127 Dirección del Trabajo, Compendio de Series Estadísticas 1990-2014. Capítulo No 1 Organizaciones Sindicales (en http://www.dt.gob.cl/documentacion/1612/w3-propertyvalue-22777.html, visto el 9 de octubre de 2015), pp. 39-40.

${ }^{128}$ Aunque de acuerdo a los datos de la Dirección Del Trabajo, ibíd, menor es aún el tamaño promedio del sindicato general, que es de 88 trabajadores. 
entre otros, el modelo de negociación colectiva y el sistema de fuero laboral de los directores sindicales.

Sin embargo, lo que llama la atención es en qué este sindicato de empresa es parte de la cultura sindical y de relaciones laborales, en cuanto no se cuestiona su existencia mayoritaria y, además, no se reivindica y no se impulsa el sindicato de carácter nacional o territorial, que es el que mayoritariamente existe en los sistema comparados de relaciones laborales, los que precisamente, permiten un sindicalismo con más poder al afiliar un mayor número de trabajadores ${ }^{129}$.

Una segunda reflexión que se plantea es el rol del Derecho frente a las relaciones colectivas de trabajo. Cierto es que de acuerdo con las categorías definidas ${ }^{130}$, la intervención del legislador en la definición de la estructura sindical se manifiesta como un instrumento de control del Estado con el fin de lograr un objetivo sociopolítico. Y así se percibe en el análisis histórico, en cuanto respecto de las leyes sociales de 1924 se considera que la legislación laboral es un "arma de doble filo"131: de un lado, se reconoce el derecho a sindicación, pero, del otro, tal legislación plantea "corporativizar y neutralizar la protesta laboral", lo que significa "que las demandas se limiten a lo estrictamente laboral" 132 .

Puede estarse de acuerdo con tales afirmaciones, dado el rol que ha tenido el Derecho del Trabajo en Chile frente a las relaciones colectivas de trabajo, el que puede imputarse tanto al antiguo modelo normativo del Código del Trabajo de 1931, como el que ha estado vigente bajo el del Plan Laboral. Sin embargo, no es ese el único rol que puede tener el Derecho del Trabajo. Excluyendo por cierto los de corte totalitario, está el Derecho que promociona los diversos institutos del Derecho Sindical y que ha sido aplicado en diversos sistemas jurídicos a través de instrumentos que han tenido eficacia al considerar precisamente los antecedentes específicos del sistema, incluido por cierto el de su cultura laboral.

\section{BiBLIOGRAFÍA}

BARRÍA, Jorge, Las relaciones colectivas del trabajo en Chile (Santiago, INSORA, Instituto de administración, Universidad de Chile, Santiago, 1967, s/e.).

BARría Jorge, Los movimientos sociales de Chile. Desde 1910 hasta 1926 (Santiago, Editorial Universitaria, 1960).

Baylos, Antonio, Derecho del Trabajo. Modelo por armar (Madrid, Ed. Trotta, 1991). CaAmaño, Eduardo, Mujer, trabajo y derecho (Santiago, Ed. Abeledo Perrot, 2011).

CETRA-CEAL, Cuadernos de Historia Popular, no 3, s/f, p. 16.

DerTo, Departamento de Relaciones de Trabajo y Desarrollo Organizacional, Universidad de Chile, Estadísticas Sindicales 1956-1972, (Santiago de Chile, s/e).

Dirección del Trabajo, Compendio de Series Estadísticas 1990-2014. Capítulo

129 Sobre esta materia véase, entre otros, GARCIA, Miguel, Relaciones laborales en Europa Occidental. Una aproximación sociológica a la transformación de sus sistemas nacionales (Valencia, Ed, Tirant lo Blanch, 2012).

${ }^{130}$ ERmida, Oscar, cit. (n. 30), pp. 379-390.

131 Mellado, Vicente, cit (n. 8), p. 96.

132 Ibíd. 
$\mathrm{N}^{\circ} 1$ Organizaciones Sindicales (en http://www.dt.gob.cl/documentacion/1612/ w3-propertyvalue-22777.html, visto el 9 de octubre de 2015).

ERMIDA, Oscar, Intervención y autonomía en las relaciones colectivas de trabajo latinoamericanas: situación actual y perspectivas, en ERMIDA, Oscar (coord.), Intervención y Autonomía en las relaciones colectivas de trabajo (Montevideo, Fondo de Cultura Universitaria, 1993).

Gaete, Alfredo, Tratado de Derecho del Trabajo chileno (Santiago, Ed. Jurídica de Chile, 1960).

Gamonal C., Sergio, Derecho Colectivo del Trabajo (Santiago, Ed. LexisNexis, 2002).

GARCIA, Miguel, Relaciones laborales en Europa Occidental. Una aproximación sociológica a la transformación de sus sistemas nacionales (Valencia, Ed, Tiran lo Blanch, 2012).

GrEZ, Sergio, El escarpado camino hacia la legislación social: debates, contradicciones y encrucijadas en el movimiento obrero y popular (Chile: 1901-1924) (2002), en http://www.memoriachilena.cl/archivos2/pdfs/MC0043163.pdf, visto el 15 de enero de 2016.

Humeres M., Héctor, Apuntes de Derecho del Trabajo y de Seguridad Social (Santiago, Décima edición, Ed. Jurídica de Chile, 1973).

Humeres M. Héctor, La huelga (Santiago, Ed. Jurídica de Chile, 1957).

Mellado, Vicente, ¡Por el derecho de asociación y huelga! La Federación Obrera de Chile (FOCH) y el camino a la legislación laboral (1921-1924, en Cuadernos de Historia 42 (2015).

Mellado, Vicente, El Código del Trabajo y los proyectos de legislación laboral de la Federación Obrera de Chile. Ponencia presentada en las XXI Jornadas de Historia de Chile 4, 5 y 6 de noviembre de 2015 (en http://www.cimtra.cl/ponencia-presentadaen-las-xxi-jornadas-de-historia-de-chile-inseguridad-estado-y-transformacionessociales-4-5-6-de-noviembre-de-2015/, visitado el 15 de enero de 2015).

Morris, James, Las elites, los intelectuales y el consenso. Estudio de la cuestión social y del sistema de relaciones industriales en Chile (Santiago, Editorial del Pacífico, 1967).

NovoA, Patricio, Seguridad Social (Santiago, Ed. Jurídica de Chile, 1978).

OJEDA, Antonio, La confrontación de modelos sociales en el cambio de siglo, en Revista Trabajo y Seguridad Social (España) 379 (octubre 2014).

Organización Internacional del Trabajo, OIT (2006). Comité de Libertad Sindical del Consejo de Administración, Recopilación de decisiones y principios del Comité de Libertad Sindical del Consejo de Administración de la OIT (5adición, Ginebra, Oficina Internacional del Trabajo).

Palomeque, Manuel, Derecho del Trabajo e ideología (7a edición, Madrid, Ed. Tecnos, 2011).

PINTO, Julio, Luis Emilio Recabarren. Una bibliografía histórica (Santiago, Ed. LOM, 2013).

Pizarro, Crisóstomo, La huelga obrera en Chile (Santiago, Ediciones Sur, 1986).

Plá, Américo, Los sindicatos en Uruguay, en Pasco, Mario y Ackerman, Mario (coords.), Los sindicatos en Iberoamérica (Lima, Ed. Aele, 1988).

Poblete, Moisés, El Derecho del Trabajo y la Seguridad Social en Chile, (Santiago, Editorial Jurídica de Chile, 1949).

Poblete, Moisés, Evolución del Derecho Social en América (Santiago, Editorial Nascimento, 1942).

Ramírez N., Hernán, Historia del Movimiento Obrero en Chile, en "Obras Escogidas Volumen I" (Segunda edición, Santiago, Ed. LOM, 2005). 
ROJAS, Irene, La legislación laboral en Chile en el ámbito de las relaciones colectivas del trabajo: control de la autonomía colectiva, en Ius et Praxis 6 (2000), 2.

ROJAS, Irene, La experiencia histórica de la negociación colectiva en Chile, en DIRECCIÓN del Trabajo (ed.), La negociación colectiva en Chile. La debilidad de un derecho imprescindible (Santiago, Ed. Dirección del Trabajo, 2008).

RoJAS, Jorge, La dictadura de Ibáñez y los sindicatos (1927-1931) (Santiago, Ed. Universitaria, Colección Sociedad y Cultura, 1993).

SALA, Tomás, Derecho Sindical (Valencia, Ed. Tirant lo Blanch, 2013).

SAlA, Tomás et alii, Derecho del Trabajo, fuentes y relaciones colectivas (4a edición, Valencia, Editorial Tirant lo Blanch, 1997).

SAlAZAR, Gabriel y Pinto, Julio, Historia contemporánea de Chile, III: La economía: mercados, empresarios y trabajadores (séptima reimpresión, Santiago, Ed. Lom, 2012).

TAPIA, Francisco, Intervención y autonomía en las relaciones de trabajo en Chile, en ERMIDA, Oscar, Intervención y autonomía en las relaciones colectivas de trabajo (Montevideo, Ed. Fundación de Cultura Económica, 1993).

Toledo, César, Tutela de la Libertad Sindical (Santiago, Ed. Thomson Reuters, 2013).

Walker E., Francisco y Arellano, Pablo, Derecho de las relaciones laborales. Un derecho vivo (Santiago, Ed. Librotecnia, 2014).

Walker L., Francisco, Esquema del Derecho del Trabajo y de la Seguridad Social (Santiago, Ed. Jurídica de Chile, 1965).

YÁÑEZ, Juan, Antecedentes y evolución histórica de la legislación social de Chile entre 1906 y 1924, en REHJ. 2 (1999).

YÁÑEZ, Juan, El Proyecto Laboral de la FOCH (1921). Los trabajadores frente a la Legislación Social, en Grez, Sergio (ed.), Espacio de convergencia, Primer y Segundo Encuentro de Estudios Humanisticos para investigadores jóvenes (Santiago, agosto de 1999 y agosto de 2000), Santiago, Ed., Museo Vicuña Mackenna, 2001).

\section{DOCUMENTOS}

Proyecto de Lei de Reglamentación del Trabajo, Presentado a la Cámara de Diputados en sesión de 26 de diciembre de 1901, por Malaquías Concha, en Boletín de la Sociedad de Fomento Fabril, año XX (Santiago, 1903), 1, pp. 23-25.

Proyecto de Contrato de Socialización Industrial, publicado en el periódico El Despertar de los Trabajadores, Iquique, $1^{\circ}$ de marzo de 1921.

Proyecto de Tribunal de Conciliación, publicado en el periódico La Gran Federación Obrera de Chile, Santiago, 7 de enero de 1921.

Proyecto de Ley de Partido Conservador. Acta del Senado, Ordinaria, 1919, pp. 40 ss.

Proyecto de Ley de Alianza Liberal. Actas de Cámara de Diputados, Ord. 1921, pp. 63 ss.

Proyecto de Código del Trabajo y de la Previsión Social, Actas de Cámara de Diputados, Ord. 1921, Sesión 2a, 4 de junio de 1921. Anexo.

Acuerdo de Comisión Mixta, véase: (1) Acta de Cámara de Diputados, Extraordinaria, 1921.22, p. 640, sesión 20, y pp. 687 a 691. Sesión 22 (30 de noviembre y 1 de diciembre de 192, se acuerda invitar al Senado a nombrar una Comisión Mixta para que estudie los Proyectos sobre Legislación Social).(2) Acta de Senado, Extraordinaria, 1921-22, pp. 552-553, sesión 41 (se acepta invitación de la Cámara de Diputados). 
Informe del Proyecto del Contrato de trabajo fue efectuada el 29 de julio de 1922, en presentación en sesión de 6 de junio de 1923 (Acta de Cámara de Diputados, 1923, Ordinaria, pp.48, Sesión 2.

Informe de Comisión Mixta, Acta de Cámara de Diputados, 1923, Ordinaria, pp.4854, Sesión 2. 